\title{
LOW GRADE UROTHELIAL CARCINOMA; CYTOLOGICAL FEATURES DISCRIMINATING FROM ATYPICAL UROTHELIAL CELLS. amjadalikhan52@hotmail.com
}

1. MBBS, FCPS

Assistant Professor of Pathology. Jinnah Medical College Peshawar.

2. MBBS, MPhil, PhD.

Professor of Pathology.

Jinnah Medical College Peshawar.

3. MBBS, FCPS, FRCS

Professor of Surgery.

Jinnah Medical College Peshawar.

4. MBBS, MPhil.

Professor of Physiology.

Jinnah Medical College Peshawar.

Correspondence Address:

Dr. Amjad Ali Khan

MBBS, FCPS.

Assistant Professor of Pathology.

Jinnah Medical College Peshawar.

amjadalikhan52@hotmail.com

Article received on:

14/10/2015

Accepted for publication:

15/05/2016

Received after proof reading:

$14 / 11 / 2016$

\section{Dr. Amjad Ali Khan ${ }^{1}$, Dr. Abdul Shaheed Asghar ${ }^{2}$, Dr. Muhammad Ishaq ${ }^{3}$, Dr. Israr Ahmed Akhund ${ }^{4}$}

ABSTRACT... Objectives: Urine cytology is an easy to perform non-invasive screening test for patients who are suspected of having urinary tract malignancy. Urothelial carcinoma constitutes approximately $90 \%$ of all primary tumors of urinary bladder. 1 High-grade urothelial carcinomas are represented by well characterized cytological features. Whereas cytological features for low-grade urothelial carcinomas show considerable overlap with features secondary to chronic inflammation, calculi, indwelling catheters or effects of intra-vesical chemotherapy.2 The purpose of this study is to find an appropriate set of cytological features of shed urothelial cells that will be useful to differentiate low-grade urothelial carcinoma cells from atypical urothelial cells secondary to non-neoplastic conditions. Study Design: Retrospective study. Setting: Charsada Teaching Hospital affiliated with Jinnah Medical College Peshawar. Period: 2010 to 2015. Methods: All cases of urine and bladder washing cytology were retrieved for three diagnostic categories namely: low-grade urothelial carcinoma (LGUC), high-grade urothelial carcinoma (HGUC), and "atypical urothelial cells"; for which histological diagnoses were also available. These cases were reviewed for cell clusters with smooth or irregular community borders, cytoplasm texture, nucleomegaly, high nucleus to cytoplasm ratios (N/C ratio), presence of nucleoli, nuclear membrane irregularity, and chromatin texture. Results: Cell clusters with smooth borders were common in reactive changes, whereas irregular community borders were seen in low-grade urothelial carcinomas and dyscohesive pattern was a feature of HGUC. The increase in N/C ratio $>2: 1$ was always associated with malignancy. The nuclear membrane irregularity was also a strong indicator of malignancy. Cytoplasmic homogeneity and nuclear hyperchromasia were more prominent and consistently seen in high-grade urothelial carcinomas. Conclusions: The study showed that nuclear membrane irregularity, nucleomegaly and high N/C ratio of > 2:1 were the most consistent features found in LGUC. These features can be used with high certainty to differentiate LGUC (malignant) from atypical urothelial cells (non-neoplastic).

Key words: $\quad$ Low-grade urothelial carcinoma, atypical urothelial cells, urine and bladder washing cytology, nuclear cytoplasmic ratio.

Article Citation: Khan AA, Asghar AS, Ishaq M, Akhund IA. Low grade urothelial carcinoma; cytological features discriminating from atypical urothelial cells. Professional Med J 2016;23(11):1323-1327. DOI: 10.17957/TPMJ/16.3126

\section{INTRODUCTION}

Urine cytology is a non-invasive and convenient test to perform as an outdoor procedure. It only requires a mid-day or second pass mid-stream urine collected in a clean bottle and brought to the laboratory without delay. It is presently considered an essential component of workup for hematuria. ${ }^{2}$ However, the test is marred by its low sensitivity, though it has high reported specificity. The sensitivity increases when more than one specimen is examined. ${ }^{2}$ The sensitivity of cytology for detecting low-grade urothelial tumors using standard criteria is about $30 \%$ and the specificity about $80 \%{ }^{2}$

Morphologically, diagnosis of high-grade urothelial carcinoma is usually straightforward; whereas, diagnosis of low-grade urothelial carcinoma is mostly baffling. The cytological features suggestive of low-grade urothelial malignancy are usually overlapping with features secondary to reactive conditions, which makes the cytological diagnosis of LGUC difficult and uncertain. ${ }^{2,3,4}$ Over the years, various cytological features have been studied to identify a useful set of features that might be helpful in reaching an appropriate diagnosis. 
The purpose of this study is to find which cytological features are more predictive of a diagnosis of LGUC over reactive changes (by studying histologically confirmed cases of LGUC). These identified features can then be used to diagnose cases of LGUC more effectively without losing them to the atypical urothelial cell group (false negative)

\section{METHODS}

In a retrospective study over a period of five years extending from 2010 to 2015; all cases (glass slides and printed reports) of urine cytology were retrieved from archives of Charsada Teaching Hospital affiliated with Jinnah Medical College Peshawar. The search was made for three diagnostic categories namely: LGUC, HGUC, and "atypical urothelial cells" for which histological diagnoses were also available. Other positive cytology cases without corresponding histological diagnoses, atypical urothelial cells cytology cases without corresponding biopsy, or cytology cases showing normal morphology were not included in the study. All the smears were re-examined and evaluated for the following features: cell clusters with smooth or irregular community borders, cytoplasm texture (whether homogeneous or vacuolated), nucleomegaly, high nucleus to cytoplasm ratios (N/C ratio), presence of nucleoli, nuclear membrane irregularity, and chromatin texture. All the specimens were second pass and mid-stream urine specimens. As a cytology laboratory policy, all the specimens that are expected to encounter delayed processing are either put in the refrigerator or $50 \%$ ethanol is added to the specimen in equal amount. All the smears had been prepared by well mixing the specimen and preparing a minimum of two cyto-centrifugation smears. At least one smear would be stained by Diff-Quick stain (to help identify the different cell types usually present in the smears) and the rest of the smears by Papanicolaou stain (used to highlight nuclear features).

\section{RESULTS}

All the smears with corresponding histological diagnoses (low-grade, high-grade urothelial carcinomas as well as atypical urothelial cells) were reviewed. The noted features are depicted in Table-l. For urothelial carcinomas, the most consistent diagnostic features were; nucleomegaly, high N/C ratio, and irregular nuclear membranes, these features were present in all (100\%) malignant cases. Cell clusters with irregular community borders were more frequent in low-grade urothelial carcinomas (100\%) than atypical urothelial cells (18\%); whereas, dyscohesive pattern was more prominent in HGUC. The increase in N/C ratio of $s: 1$ (i.e nuclear diameter more than half the cell diameter) was always associated with urothelial malignancy $(100 \%)$, though uncommonly, it can also be associated with atypical urothelial cells (18\%). The nuclear membrane irregularity either unifocal or multifocal was also a strong indicator of malignancy (100\%), very uncommonly this feature can be noted in atypical urothelial cells $(9 \%)$. Other features like cytoplasmic homogeneity (50\%), nucleolar prominence (78\%), and hyperchromatic nuclei (100\%) were more common in high grade urothelial carcinomas.

\section{DISCUSSION}

Urine cytology was first used by Wilhelm Duschan Lambl, a Czech physician in 1836 who described cellular details of malignant cells in urine. ${ }^{3}$ Urine cytology was further described and popularized as a diagnostic tool by Papanicolaou and Marshall in 1945, marking the revival of this technique. ${ }^{3}$ Much work has been done since then to define various cytological features to identify high- or low-grade urothelial carcinomas. The diagnosis of high-grade urothelial carcinomas is usually straightforward as the degree of pleomorphism is marked and quite apparent. ${ }^{2}$ The diagnosis of LGUC is, however, difficult because the cellular pleomorphism is mild enough to be confused with the features of benign reactive atypia.

The normal urine and bladder washings contain variable number of superficial and intermediate bland urothelial cells Figure-1. The most important cytological feature consistently seen in low and high-grade urothelial carcinoma was irregularity of nuclear membranes Table-l. It appeared as nuclear indentations or notches at single or multiple points along the nuclear 
membranes Figure-2. The nuclear membrane in atypical urothelial cells was almost always uniform and smooth. The second important feature was nucleomegaly, nuclei mostly appeared as enlarged, elongated and eccentric, leading to high $\mathrm{N} / \mathrm{C}$ ratio. The normal $\mathrm{N} / \mathrm{C}$ ratio for urothelial cells is usually $1: 3$ to $1: 4$; whereas, in lowgrade urothelial carcinoma the $\mathrm{N} / \mathrm{C}$ ratio is $>2: 1$ Figure-3. That is, the nuclear diameter is more than half the cellular diameter for most of the cells in the crowded cell clusters. The nuclei in atypical urothelial cells were enlarged but the $\mathrm{N} / \mathrm{C}$ ratio was always < 2:1 and the nuclei were largely rounded and centrally located Figure-4. The importance of these features has been variously reported in the

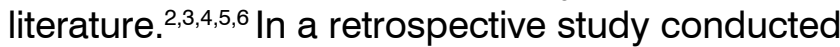
at University of lowa Hospitals and Clinics from 1991 to 1994, a stepwise logistic regression analysis was utilized and three cytological features were identified as most useful in discriminating low grade urothelial carcinoma from non-neoplastic lesions. These identified features were increased $\mathrm{N} / \mathrm{C}$ ratios, irregular nuclear membranes, and cytoplasmic homogeneity. ${ }^{7}$ Similarly in another study conducted at the University of Michigan, Medical Center, urine and bladder wash cytology cases processed by liquid based cytology were reviewed retrospectively from the years 1995 to 2001. It was found that high $\mathrm{N} / \mathrm{C}$ ratio, irregular nuclear membrane, and cytoplasmic homogeneity were three important diagnostic features for LGUC even in Thin Prep samples. ${ }^{8}$ These three features in combination had a sensitivity of $59 \%$ and a specificity of $100 \% .^{8}$ Necrosis though rarely seen in such samples was present only in carcinomas. ${ }^{8}$ The results inferred from our study are in accordance with these two studies.

\begin{tabular}{|c|c|c|c|c|c|c|c|c|}
\hline $\begin{array}{c}\text { Diagnostic } \\
\text { Category }\end{array}$ & $\begin{array}{l}\text { Cases } \\
\text { (n) }\end{array}$ & $\begin{array}{l}\text { Cell clusters with } \\
\text { irregular } \\
\text { Community borders }\end{array}$ & $\begin{array}{l}\text { Cytoplasm } \\
\text { homoge- } \\
\text { neity }\end{array}$ & $\begin{array}{l}\text { Nuclear } \\
\text { membrane } \\
\text { Irregularity }\end{array}$ & $\begin{array}{l}\text { High } N / C \\
\text { ratio } \\
>2: 1\end{array}$ & $\begin{array}{l}\text { Nucle- } \\
\text { omegaly }\end{array}$ & Nucleoli & $\begin{array}{l}\text { Coarse } \\
\text { chromatin }\end{array}$ \\
\hline $\begin{array}{l}\text { High Grade } \\
\text { Urothelial } \\
\text { Carcinoma }\end{array}$ & $n=14$ & 10 (71.4\%) & 7 (50\%) & 14 (100\%) & $14(100 \%)$ & $\begin{array}{c}14 \\
(100 \%)\end{array}$ & $\begin{array}{c}11 \\
(78.6 \%)\end{array}$ & $14(100 \%)$ \\
\hline $\begin{array}{c}\text { Atypical } \\
\text { Urothelial Cells }\end{array}$ & $n=11$ & 2 (18.2\%) & 4 (36.4\%) & $1(9.1 \%)$ & 2 (18.2\%) & $6(54.5 \%)$ & 5 (45.5\%) & $2(18.2 \%)$ \\
\hline
\end{tabular}

Table-I. Cytological Features in Urine and Bladder Wash Cytology. 
The third most important cytological feature found in low-grade urothelial carcinoma and more so in high-grade urothelial carcinoma was the presence of hyperchromatic nuclei Figure-3 in the form of intense staining, coarsely granular and clumped chromatin leading to irregular distribution of chromatin in the nuclei. In atypical reactive urothelial cells, the chromatin is mildly hyperchromatic and finely granular. Raab et al. in their study found that hyperchromatic and eccentric nuclei were more helpful features when used in conjunction with nuclear membrane irregularity, high $\mathrm{N} / \mathrm{C}$ ratio and cytoplasmic homogeneity. ${ }^{8}$ Unaccompanied by other features, hyperchromatic nuclei can be seen in some cases of reactive atypia as well, Table-l.

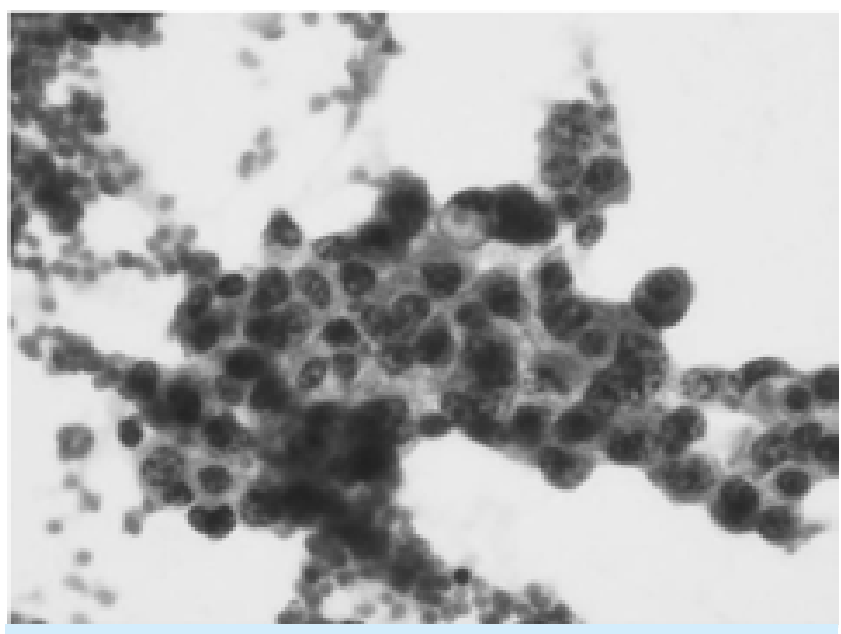

Figure-3. High N/C ratio, hyperchromatic and enlarge nuclei. Papanicolaou stain, $\mathbf{x 4 0 0}$

An important architectural feature of low-grade urothelial carcinoma was the presence of small to large cell clusters having irregular community borders Fig 5, its component cells showed mild to moderate nuclear disarray. While in high-grade urothelial carcinoma, similar cell clusters showed more dyscohesive cells in addition to significant number of single cells. Cell fragments of various sizes have been described in the literature varying from 4 to several cell wide ${ }^{5}$, whatever the fragment sizes, irregular community borders are predictive of malignancy.

\section{CONCLUSION}

The cytoplasmic homogeneity was not an important feature in our study as it was not

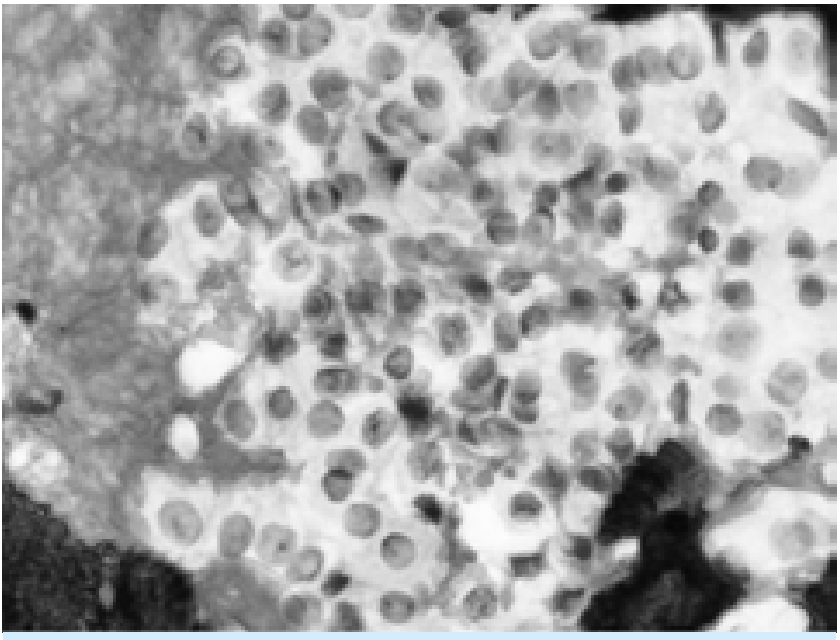

Figure-4. Atypical urothelial cells (non-neoplastic). Papanicolaou stain, $\mathbf{x} 400$.

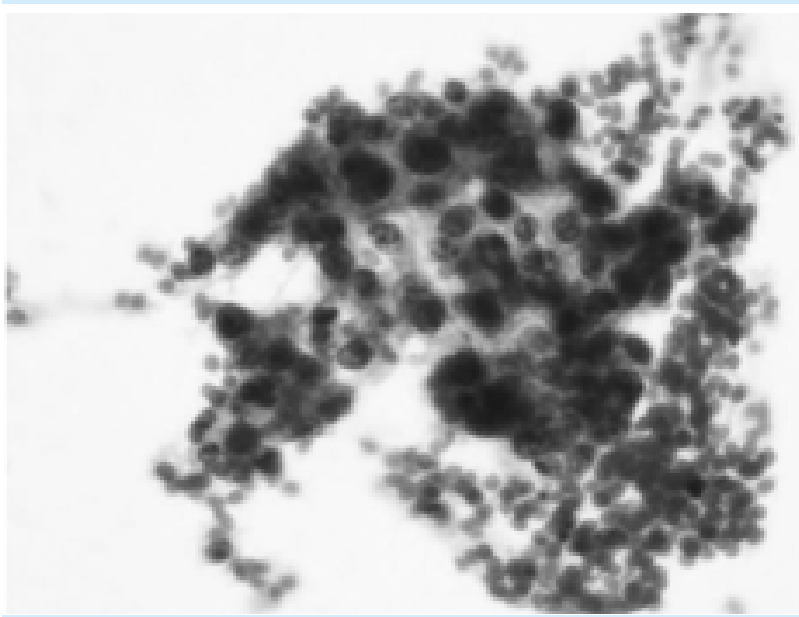

Figure-5. Cell clusters with irregular community borders. Papanicolaou stain, x200.

reproducible; it was more subjective and depended on the specimen type. We found the cytoplasm always to show some element of vacuolization especially in voided urine specimens as compared to bladder washings. The cytoplasm was more dense and homogenous though scanty in high grade tumors. This is however, contrary to what has been reported in the literature and in various studies. ${ }^{2,3,4,5,6}$ The possible reasons for this discrepancy can be: the use of conventional cytology techniques instead of liquid based cytology, increased number of voided urine specimens as compared to bladder washings in this study, poor preservation of the specimen, possible delay in specimen processing in our study with early onset of degenerative 
changes, or a smaller set of specimens studied. However, a larger specimen group study would be more appropriate in order to study this feature in specific.

The other cytological features like prominence of nucleoli, nuclear molding, anisonucleosis etc. are not helpful in distinguishing low-grade urothelial carcinoma from reactive changes on their own. However, they could be considered as minor diagnostic features that are helpful only in the presence of some of the more important above mentioned cytological features..$^{8,9,10}$ The reactive changes in our study were mostly encountered secondary to vesical calculi, chemotherapy, and indwelling catheters.

In conclusion, the most important diagnostic cytological features in favor of low-grade urothelial carcinoma over atypical urothelial cells were irregular nuclear membranes, nucleomegaly with increased $\mathrm{N} / \mathrm{C}$ ratio above $2: 1$, and cell clusters (when present) with irregular community margins. However, still there will be cases which will be borderline and difficult to differentiate, where cystoscopic biopsy should be suggested to clinch the diagnosis.

Copyright(C) 15 May, 2016.

\section{REFERENCES}

1. Nelson GO, Juan R. Urinary tract: Kidney, renal pelvis, and ureter; Bladder. In: Juan Rosai. Rosai and Ackerman's Surgical Pathology (10th Edition). Elsavier: 2011: 1257-1265.
2. Renshaw AA. Urine and Bladder Washings. In: Cibas ES, Ducatman BS. Cytology Diagnostic Principles and Clinical Correlates. Saunders. 3rd edition 2009:115-122.

3. Khalbus WE, Monaco SE, Pantanowitz L. Urine Cytopathology. In: Quick Compendium of Cytopathology. ASCP press. 2103:199-208.

4. Leopold GK, Myron RM. Koss' Diagnostic Cytology and Its Histopathologic Bases. Lippincott Williams \& Wilkins, 5th edition. 2006:793-802.

5. Marluce Bibbo and William H. Kern, Urinary Tract. In: Marluce B, David CW. Comprehensive cytopathology. Saunders, 3rd edition. 2008:415-423.

6. Bardales RH. Practical urologic cytopathology. Oxford University Press. 2002:144-150.

7. Stephen SR, Julia CL, Michael BC. Low Grade Transitional Cell Carcinoma of the Bladder, Cytologic Diagnosis by Key Features as Identified by Logistic Regression Analysis. Cancer, 1994, Volume 74, No. 5.

8. Wei X, Stephen SR and Claire WM. Low-Grade Urothelial Carcinoma: Reappraisal of the Cytologic Criteria on ThinPrep ${ }^{\circledR}$. Diagnostic Cytopathology, 2003, Vol 29, No 3.

9. Michelle DR, Adeboye O, Momin TS, Stephen WL. Accuracy of grading of urothelial carcinoma on urine cytology: an analysis of inter-observer and intra-observer agreement. Int J Clin Exp Pathol, 2012; 5(9):882-891.

10. Jonathan $\mathrm{HH}$, Stephen SR, Michael BC. The Cytologic Diagnosis of Low-Grade Transitional Cell Carcinoma. Am J Clin Pathol 2000; 114 (Suppl 1):S59-S67.

\section{AUTHORSHIP AND CONTRIBUTION DECLARATION}

\begin{tabular}{|c|c|}
\hline Sr. \# & \multicolumn{1}{|c|}{ Author-s Full Name } \\
\hline 1 & Dr. Amjad Ali Khan \\
2 & Dr. Abdul Shaheed Asghar \\
3 & Dr. Muhammad Ishaq \\
4 & Dr. Israr Ahmed Akhund \\
\hline
\end{tabular}
Contribution to the paper

Author $=$ s Signature

Design, data, drafting \& financial support Design, data analysis, menuscript revision \& supervision

Design, data analysis, supervision

Design, data revision, supervision

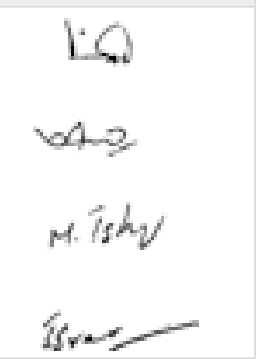

